\title{
A REPRESENTAÇÃO DA MORTE NOS CONTOS DE CADERNO NEGROS, V. 34
}

\author{
Miriam Alves ${ }^{1}$
}

Resumo: O presente artigo empreende análise dos contos reunidos no volume 34 da Cadernos Negros, publicação cooperativada de escritores negros dos mais diversos pontos do Brasil, reunidos em torno do selo editorial Quilombhoje Literatura. Dos 22 contos do volume 34, a análise se detém naqules que tematizam a morte.

Palavras-Chave: Cadernos Negros, Contos, Morte.

Resumen: El artículo analiza cuentos compilados en el número 34 de la Revista Cadernos Negros, editada en forma cooperativada por escritores negros brasileños, reunidos en torno al editorial Quilombhoje Literatura. El tema de la muerte es lo que se destaca de los 22 cuentos del número 34 de Cadernos Negros, siendo el foco del análisis.

Palabras-llave: Cadernos Negros, Cuentos, Muerte.

Como aqui a morte é tanta, só é possivel trabalhar

João Cabral de Melo Neto, Morte e vida Severina

A morte, surda, caminha ao meu lado

E eu não sei em que esquina ela vai me beijar

Raul Seixas, Canto para minha morte

A morte é rainha que reina sozinha

Não precisa do nosso chamado

Gilberto Gil, A morte

A música da Morte, a nebulosa, estranha, imensa música sombria

Cruz e Souza, Música da Morte

Quando eu morrer

Não quero choro nem vela,

Quero uma fita amarela

Gravada com o nome dela (Noel Rosa, Fita amarela).

1 Escritora. 


\section{INTRODUÇÃO}

Ano de 2011: no dia 15 de dezembro veio ao público, no evento da Feira Preta ${ }^{2}$, em São Paulo, o volume 34 de Cadernos Negros ${ }^{3}$. Muito se tem falado e escrito sobre a persistência aguerrida dessa coletânea que, ao longo de quase três décadas e meia, tem mantido vivo o espírito coletivo de uma literatura negra que ajudou a fomentar por meio da publicação de poemas e contos. A reflexão sistemática ali promovida, nos mais diversos momentos, sobre o fazer literário, envolve profissionais na maioria negros, dos mais variados campos de atuação do conhecimento, tendo como ponto de partida os autores e autoras com suas prosas curtas e seus versos.

Ao longo desses anos, Cadernos Negros vem atraindo um número significativo de leitores, seguidores e estudiosos de literatura tanto no território nacional como fora do país, como nos Estados Unidos, Alemanha, França, Angola. A edição especial intitulada Cadernos Negros Melhores Poemas, de 2008, reúne trabalhos de autores publicados nos volumes de 1 a 19 , que estão esgotados ${ }^{4}$, e constou da lista de livros para o vestibular de

2 Feira Preta é a maior feira de cultura negra da América Latina, comemorou dez anos em 2011. Sua primeira e segunda edição aconteceram na Praça Benedito Calixto, Vila Madalena em São Paulo, reunindo nesses dois momentos por volta de 12 mil pessoas; na terceira edição, um abaixo assinado realizado pela associação dos amigos da praça e moradores do bairro exigiu que o evento não acontecesse mais naquele local, alegando ser inapropriado o "tipo de cultura" fomentado. A partir deste fato, a feira mudou o formato, sendo realizada a cada ano em diferentes espaços, até ser sediada por quatro anos no Anhembi Parque - Centro de Eventos e Convenções da Cidade de São Paulo, do qual saiu por ter ficado pequeno pelo número de frequentadores. Atualmente é realizada no Centro de Exposição Imigrantes, um dos mais modernos espaços para realização de eventos da América Latina, reunindo vários segmentos do empreendedorismo negro de grandes, micro e pequenas empresas, tais como: vestuário, calçados, acessórios, gastronomia, literatura, produtos de beleza, artesanato, entre outros. Representa uma forte conquista no processo de autovalorização do negro, público junto ao qual se encontra consolidada. Em 2012, numa parceria firmada com o Coletivo de Clubes Sociais Negros do Rio Grande do Sul, a Feira se realizará nos dias 8 e 9 de setembro, em Porto Alegre (RS).

Os Cadernos Negros, publicação cooperativada de escritores negros dos mais diversos pontos do país. Os números apresentam alternativamente poemas (números pares) e contos os números ímpares). O número 34, com 21 autores e 22 contos, corresponde ao trigésimo quarto ano de publicação dessa coletânea (desde 1978).

4 Cf. http://www.quilombhoje.com.br/oslivros/resenhamelhorespoemas.htm. Acesso em: jan. 2012.

188 Número temático: Literatura, cultura e memória negra. A Cor das Letras - UEFS, n. 12, 2011 
2008/2009 da Universidade Federal da Bahia - UFBA, por iniciativa do Departamento do Instituto de Letras ${ }^{5}$.

Fazem parte deste número Ademiro Alves (Sacolinha), Adilson Augusto, Claudia Walleska, Conceição Evaristo, Cristiane Sobral, Cuti, Débora Garcia (estreante em CN), Denise Lima (estreante em CN), Claudia Walleska, Conceição Evaristo, Elizandra Souza, Esmeralda Ribeiro, Fátima Trinchão, Fausto Antônio, Guellwaar Adún (estreante em CN), Henrique Cunha Jr, Jairo Pinto, Luis Carlos "Aseokaýnha”, Mel Adún, Mighian Danae (estreante em CN), Miriam Alves, Onildo Aguiar, Thyko de Souza. Alguns deles possuem larga experiência e extenso currículo de publicação e vivência literária, com participação em seminários e congressos, organização de antologias e livros de textos críticos onde vários aspectos da literatura negra são teorizados e debatidos; três autoras estréiam com seus contos, outros autores publicam pela segunda vez nos Cadernos Negros, organizado pelo Quilombhoje Literatura seguindo princípios do cooperativismo ${ }^{6}$.

A riqueza no tratamento dos temas revela a diversidade de experiência entre os autores que ora publicam neste volume 34 , tendo como eixo principal a vivência do negro brasileiro em suas infinitas possibilidades de sentimentos e ações, imprimindo ao livro uma coerência no ato da escrita. Entre os temas escolhidos pelos autores, o que deteve minha atenção foi a tematização da Morte, por estar presente em seis dos vinte e dois textos publicados. Passei a refletir sobre a representatividade que o ato de morrer assume na ficção da literatura negra, na qual os autores se predispõem a visibilizar a voz e sentimento da população afrodescendente. Relembrei a época em que trabalhava como assistente social no Hospital das Clínicas em São Paulo, quando participei de um grupo de estudo que se predispunha a estudar os vários entendimentos do morrer, visando instrumentalizar teoricamente os profissionais que trabalham com pacientes terminais e com parentes de vítimas de mortes traumáticas.

Naquela ocasião percebi, através do estudo e da observação, de como a Morte adquire significados diferentes, dependendo da cultura, religião e, lógico, da reação individual das pessoas que se deparam com esta

5 Cf. http://oaprovado.blogspot.com/2008/07/lista-de-livros-para-vestibular-ufba.html. Acesso em: jan. 2012.

6 Segundo definições do SEBRAE: "Cooperativa é uma associação autônoma de pessoas que se unem, voluntariamente, para satisfazer aspirações e necessidades econômicas, sociais e culturais comuns, por meio de um empreendimento de propriedade coletiva e democraticamente gerido" (Cf. http://www.sebraemg.com.br/culturadacooperacao/co operativismo/cooperativa\%20o\%20que\%20e.htm. Acesso em: jan. 2012). 
realidade imutável da vida; atentei também para a mudança dos rituais de despedidas, através dos tempos, daqueles que morrem ${ }^{7}$. Por exemplo, antes, os velórios eram feitos nas casas, com a presença de parentes e amigos que se despediam dos seus mortos com choro e velas. A falecida ou o falecido tinham a vida comentada e lembrada por aqueles que fizeram parte emocional de sua trajetória; depois, em cortejo fúnebre, eram levados até a última morada, como se costumava dizer. Atualmente, principalmente nos grandes centros urbanos, se morre entre os profissionais de saúde que são estranhos ao moribundo ou moribunda, ou seja, uma morte socialmente asséptica e solitária ${ }^{8}$, como tive a oportunidade de presenciar na minha prática como assistente social.

Com relação ao tema da Morte em Cadernos Negros, volume 34, as situações do morrer abordadas pelos autores assumem os mais diversos significados, alguns dos quais abordarei aqui neste artigo.

\section{A MORTE OBSERVADA COMO INQUIETAÇÃO E INDAGAÇÃO DA VIDA: $A$ SOLIDÃO DE SOLEDADE, DE GUELLWAAR ADÚN ${ }^{9}$}

Neste conto do baiano Guellwaar (p. 99-106), a morte aparece para a personagem Adeilton como inquietação ao observar uma pintura de um quadro intitulado $O$ primeiro passo para a independência da Bahia onde, em meio a cadáveres de uma possível batalha, retratada como um grande feito heróico, Adeilton se atém com atenção ao "homem negro como ele, estirado no chão, parecendo dizer suas últimas palavras a um sujeito fardado que o acompanhava em seus últimos momentos de dor". Mais tarde, numa outra situação, fica sabendo que o nome do negro que jazia no chão é Soledade, o Tambor Soledade, um possível herói daquele fato histórico.

7 Sobre o assunto, o livro de João José REIS, A morte é uma festa (1991), apresenta uma minuciosa descrição de como era feita, na Bahia no século XIX, a preparação do defunto, as formas e os lugares de enterramento, os cortejos, velórios, missas, evidenciando que a substituição dos cortejos coletivos a pé pelo uso de carros funerários marca uma transformação social na maneira de conceber a morte para um estilo menos festivo.

Elisabeth Kübler-Ross, no capitulo I do livro Sobre a morte e o morrer, afirma: "Morrer se torna um ato solitário e impessoal, porque o paciente é removido de seu ambiente familiar e levado às pressas para uma sala de emergência. O caminho para o hospital é o primeiro capítulo da morte".

9 Guellwaar Adú, pseudônimo de Marcus Gonçalves da Silva, nasceu no Rio de Janeiro em 29 de dezembro ANO. Filho de família imigrante da Bahia. Atualmente mora em Salvador, é educador, compositor, produtor e vocalista da Junça da Pedra Preta do Paraguassú.

190 Número temático: Literatura, cultura e memória negra. A Cor das Letras - UEFS, n. 12, 2011 
O autor vai relacionando vários episódios ligados à banalização da morte, principalmente quando o defunto é um negro:

A insensibilidade dos não-negros diante das vítimas não-pertencentes ao seu universo racial era velha conhecida daquele rapaz, salvo raríssimas exceções. Lembrava-se das inúmeras "marchas pela paz", nascidas depois de alguma perda importante para os brancos, de forma violenta. No entanto, o silêncio e a balanalização diante das muitas baixas ocorridas em seu bairro e "em tantas outras quebradas", como ele gostava de enfatizar, faziam parte da quimera carnavalesca de sua terra[...].

A retratação da morte observada no quadro pela personagem Adailton, assim a solidão do Tambor Soledade serve como fio condutor de análise da ação genocida perpetrada contra a população negra, principalmente homens jovens, sem que as autoridades competentes apurem e punam os responsáveis. A tensão emocional da personagem Adailton desemboca em choro solitário ao constatar a indiferença social, pois "a ninguém interessava se mais um jovem negro havia, ou não sofrido, qualquer tipo de violência". Neste conto, a tematização da morte é usada para denunciar a realidade vivenciada pelos afrodescendentes.

\section{A MORTE COMO GRITO DE ALERTA CONTRA A EXECUÇÃO SUMÁRIA: ARMANDINHO, RG DESCONHECIDO, DE JAIRO PINTO ${ }^{10}$}

Eu já li em algumas teses que estudam os temas recorrentes em $\mathrm{Ca}$ dernos Negros que a tematização da violência é a mais freqüente entre os escritores que publicam nessa coletânea, mas surgiram-me novas reflexões ao ler o conto de Jairo Pinto (p. 117-119), no qual é retratada a morte da personagem Armandinho por prováveis milicianos encapuzados que invadem sua pequena casa quando ele se prepara para ir trabalhar:

Minutos depois, ao tampar a marmita, Armandinho ouviu umas pegadas cada vez mais violentas, e próximas e uma violenta pesada na porta do barraco.

Esta, ao vir abaixo, o deixou na mira de canos de uso exclusivo distribuídos em algumas mãos.

Ao ler esse trecho, é possível que um nó se faça na garganta dos mais sensíveis e que várias indagações e indignações vão tomando forma. Uma das possíveis perguntas que possa pairar na mente do leitor é: E os direitos humanos? Seguida de outra: pena de morte no Brasil? O que logo puxa

10 Jairo Nascimento Pinto, cientista social, nasceu em 1982 em Salvador, Bahia. Um dos fundadores do Núcleo de Estudantes Negras e Negros da Universidade Federal da Bahia. Estreou em Cadernos Negros, v. 33, em 2010, com cinco poemas. 
mais perguntas: É uma guerra? É um extermínio? Ninguém vê? Não fazem nada? E mais perguntas podem surgir como se fosse um rosário a ser desfiado como num velório quando se encomenda a alma do falecido.

Armandinho morre para denunciar os defuntos anônimos que pontuam as estatísticas do censo do IBGE de 2010, que afirma que o índice de morte por causas não naturais é maior entre os homens jovens negros brasileiros até os 25 anos de idade. Armandinho morre no conto de Jairo Pinto, como os vários como ele que são eleitos como suspeitos e, sem serem julgados, são executados. O autor constrói ficcionalmente a morte de um jovem negro, para que essa morte se eleve como gritos indignados: Ninguém tá vendo? Nós estamos sendo exterminados:

Foi dada a sentença: algemas descartáveis nos punhos voltados para trás! [...] Armandinho, machucado, humilhado, aflito... viajava no porta-malas daquele Fiesta prata, placa fria, acompanhado de um cadáver e mil fantasmas que rondavam sua cabeça. [...]

Armandinho foi descido do carro argumentando em sua defesa. Três dos homens encapuzados, que desceram do carro ainda tentaram arrancar nomes de Armandinho, inutilmente... [...]

Neste momento, os estampidos passaram a ressonar quebrando aquele então silêncio matinal, enquanto o corpo negro de Armandinho, rubro em sangue, ia caindo eternamente no chão.

\section{A MORTE COMO DENÚNCIA: LUMBIÁ E EI, ARDOCA, DE CONCEIÇÃO EVARISTO $^{11}$}

Com relação ao tratamento que os autores do volume 34 de Cadernos Negros dedicaram ao tema da Morte como forma de denúncia das várias situações de desumanização vivenciadas pela população afrodescendente, os contos "Lumbiá" (p. 35-40) e "Ei, Ardoca" (p. 41-44), de Conceição Evaristo são reveladores de diferentes formas de protesto, como a autoflagelação de Ardoca ou a denúncia de um genocídio não declarado e banalizado como, por exemplo, em "Lumbiá".

11 Conceição Evaristo nasceu em Belo Horizonte, reside no Rio de Janeiro desde 1973. Mestre em Literatura Brasileira pela PUC/Rio e Doutora em Literatura Comparada pela Universidade Federal Fluminense. Publicou: Ponciá Vivencio, romance (1. ed -2003, 2. ed. - 2006); Becos da memória (2008), traduzido para o inglês e publicado nos Estados Unidos; Poemas da recodação e outros movimentos (2008); Insubmissas lágrimas de mulheres (2011). Publica contos e poemas em Cadernos Negros desde 1990, muitos dos quais constam de antologias no Brasil, nos Estados Unidos, na Inglaterra, Alemanha e África do Sul.

192 Número temático: Literatura, cultura e memória negra. A Cor das Letras - UEFS, n. 12, 2011 
As situações do morrer abordadas pelos autores assumem cada vez um outro significado, apresentando-se com uma nova roupagem. "Lumbiá", o menino negro, trabalhava nas ruas de alguma de uma grande cidade vendendo amendoim e flores, observador atento do burburinho cotidiano dos transeuntes e também das vitrines hipnóticas em seus diversos apelos de compras. Na época do Natal, fascinado pelas luzes e cenas de presépio exposto numa loja, adentrou o recinto, aproximou-se da imagem do "Deusmenino", que estava nu e de braços abertos, repousado na manjedoura. Lumbiá vislumbrou semelhanças e se identificou em necessidade de afeto e acolhida com aquela imagem que despertava nele sentimentos protetores. Retirou a pequena escultura da cena do presépio para agasalhá-la e formar com ela um outro acontecimento dramático, assim descrito por Conceição Evaristo:

Tomou-a rapidamente nos braços. Chorava e ria. Era seu. Saiu da loja levando o Deus-menino. O segurança voltou. Tentou agarrar Lumbiá. O menino escorregou ágil, pulando na rua. O sinal ! O carro! Lumbiá! Pivete! Criança! Erê, Jesus-menino. Amassados, massacrados, quebrados! Deus-menino, Lumbiá morreu!

No segundo conto de Conceição Evaristo, é apresentado o morrer como atuação premeditada, ou seja, o suicídio cuidadosamente planejado na ação da personagem Ardoca que resolve sair da vida no mesmo cenário que sempre fez parte de sua existência, desde a sua concepção, quando sua mãe grávida usava o trem para se locomover do trabalho para casa diariamente, até após o nascimento do filho. Posteriormente, quando adulto, Ardoca seguia o mesmo trajeto de ir e vir sobre os trilhos imutáveis que pareciam traçar a imutabilidade de seu destino de trabalhador e morador suburbano. O barulho característico da composição se atritando nos trilhos da linha férrea, descrito pela autora, nos leva a sentir a tensão interna da personagem:

Estava sempre atento, tenso, como se o trem, a qualquer momento, pudesse se autocolidir, se autoembarafunhar, fazendo com que o último vagão se fechasse em círculo sobre o primeiro e soltasse tudo pelos ares.

Em outro trecho, a autora descreve a agitação no dia a dia da realidade vivenciada no veículo de transporte público, utilizado por centenas de vidas, com as mais variadas ações individuais e coletivas, percebida pelo protagonista como mesmice na monotonia cotidiana que desumaniza. Com plena consciência do uso da palavra como instrumento e veículo da densidade da trama, a autora vai revelando o conflito existencial de Ardoca, te- 
cendo o clima do desfecho da morte premeditada como um círculo que se completa.

Fora um ato solidário de uma das passageiras, o homem, desencantado com a própria vida, suicida-se em meio ao lufa-lufa de um trem superlotado, gesto encarado como mais um ato qualquer para os que assistem a sua breve agonia. Outro gesto, aparentemente solidário, de um indivíduo que surge de repente para socorrer o moribundo, mas acaba saqueando o defunto, é o ápice da banalização da morte e do morrer nos grandes centros urbanos descrito pela narradora: "Aquele que o socorrera estava a meter a mão nos bolsos de Ardoca e a arrancar os sapatos e o relógio que ele trazia no pulso".

E logo adiante Evaristo conclui: "Não era preciso porém nem dor, nem lágrimas. $O$ outro podia levar os poucos pertences de Ardoca. Podia tomar-Ihe tudo. Ardoca não tinha mais nada, nem a vida".

\section{A MORTE ENQUANTO METÁFORA DE RECRIAÇÃO DAS PALAVRAS E DOS CONCEITOS: O ESCURO DAS PALAVRAS, DE FAUSTO ANTÔNIO ${ }^{12}$}

A Morte, neste belíssimo conto de Fausto Antônio (p. 89-97), é evocada como metáfora da essência criativa, o lugar da busca inquietante das respostas e da precisão imprecisa da memória onde a procura se formaliza em criação: "quem toca para subir ou descer a memória é um criador. Mas o criador, a exemplo da morte, destrói ou reinventa o criado".

Com o título "O escuro das palavras", o autor reinventa e imprime positividade ao termo escuro, visto como o lugar da criação onde a

Fala! Fala é grita ${ }^{13}$, no silêncio profundo e inacabado fulgor, um texto que não se entende, que não se repete senão na fissura dele e vai se erguendo num escuro de criação, de sangue pulsante.

A concepção de Morte, utilizada na elaboração no conto, não é entendida como o fim, antes de tudo é uma recriação da vida, um recomeço. O trecho a seguir dá algumas pistas quando a protagonista Kaya se depara com a morte da avó:

12 Fausto Antônio nasceu em Campinas, São Paulo. Doutor em Teoria Literária pela UNICAMP. Publicou: Fala de de pedra a pedra, poesia (1986); Linhagem de peda e outra pessoa (1991); Exunos, romance (1995); participou de Cadernos Negros com contos e poemas nos anos de 1997, 2000, 2001, 2004, 2009 e 2011.

13

O termo grita é um dos sinônimos para o substantivo feminino gritaria, utilizado como expressão popular "grita geral", principalmente nas zonas urbanas de São Paulo.

194 Número temático: Literatura, cultura e memória negra. A Cor das Letras - UEFS, n. 12, 2011 
Não eram os mortos; eram os ancestrais. A avó era a criação e a restituição, a vida e a morte, a própria existência. Era como se a velha falasse através da neta: agora, estou aqui para despertar o escuro das palavras.

Fausto Antônio comunica utilizando-se de elementos simbólicos que vão construindo um canal direto para falar com nossas emoções que são capturadas, antes de nos apercebermos e vão se enredando no conteúdo da mensagem grafada nas palavras e sentenças. Ao denominar a personagem com o nome Kaya,o autor indica os caminhos da narrativa que vão ser traçados. Segundo a mitologia, Kaya é o mesmo que Gaia, e significa a Mãe Terra para onde se retorna após a morte, para renascer em novos significados. Assim sendo:

[...] havia os artifícios em face da morte da avó e de outras mortes que renasciam, no entanto, no presente. Então não era apenas morte, era a vida. Ou era o jogo, vida e morte, que até agora Kaya tinha cuidadosamente suprimido ou alimentado?

Enfim, este é um dos contos ${ }^{14}$, entre os seis outros que tematizam a morte e o morrer publicados nos Cadernos Negros, volume 34, no qual a Morte não é relatada através de fatores de violência, extermínio, miséria, balas perdidas, punição divina e outros, é antes de tudo uma recuperação da concepção de culturas africanas onde a Morte é um elemento da vida e os que se foram não desaparecem, se tornam ancestrais.

\section{CONCLUSÃO}

A Morte é um elemento importante na cultura humana, assim como a vida, sempre esteve presente nas manifestações artísticas, direta ou indi-

14 Na verdade, são cinco autores e seis textos, no conjunto do volume 34 de Cadernos Negros, que tratam da temática da Morte. Não me sinto à vontade para comentar a minha própria estória ("O velório", p. 143-150), que trata do velório de Dona Patrocina, matriarca respeitada e apoio emocional da família, batalhadora incansável, com a autoridade de conselheira, possuidora das chaves dos fundamentos herdados dos antepassados segundo as tradições orais das culturas africanas. Neste conto, relato a cerimônia da última despedida, registrando as manifestações rituais, tanto os baseados nas religiões afrodescendentes, bem como os popularizados da liturgia católica, como por exemplo, rezar o terço. Costumes hoje em dia cada vez menos usuais, principalmente nos grandes centros urbanos, quando para os velórios são reservados, geralmente, um recinto anônimo ao lado dos cemitérios. No entanto o costume de "velar o morto", nas residências, ainda é freqüente nas comunidades rurais e mesmo nas grandes cidades, nas famílias mais ligadas às tradições ancestrais. 
retamente. Na criação literária do ocidente,nos diferentes períodos, configura-se nas mais diversas maneiras, como por exemplo: punição para os vilões; para glorificar os heróis; como união dos amantes que não poderiam ser felizes em vida; enquanto contraponto à vida; como uma ameaça constante cruel e imperdoável; como um fenômeno a ser temido e vencido; como forma de fuga de um mundo imperfeito para um mundo idealizado; busca pela espiritualidade; com o caráter de social e de revolta; e por fim, como um fenômeno sobrenatural capaz de assombrar as pessoas. Atualmente através dos filmes, jogos eletrônicos e programas de televisão instituiu-se a banalização da morte, principalmente as de forma violenta, ou consequência de grandes catástrofes, conflitos e guerras, o que transforma o ato de morrer num espetáculo impessoal próximo e distante ao mesmo tempo.

Em Cadernos Negros, de forma geral, ao longo destes trinta e quatro anos, o tema da Morte freqüentemente pontilhou poemas e contos na escrita dos autores, quase sempre é um grito de alerta, uma denúncia contra as desigualdades, ora registrando o genocídio dos africanos e descendentes ocorrido no período do sistema escravista mundial, ora denunciando a eugenia que norteia as ações violentas e exterminadoras das sociedades contemporâneas contra a população negra nacional e internacional; outras vezes ainda o tema é trabalhado como ocorrência que impede a convivência familiar ou os encontros amorosos.

Os escritores e escritoras abordados neste artigo enfrentam as controvérsias do tema da Morte transformando-o, criativamente, num fio condutor narrativo de grande tensão. Nos contos $A$ solidão de Soledade, de Guellwaar Adún; Ei, Ardoca, de Conceição Evaristo, além dos elementos característicos acima descritos, percebe-se a presença explícita de um questionamento existencial. No primeiro, há uma inquietação um interrogar de sentidos da vida frente a presença iminente da morte. No segundo, a própria construção narrativa demonstra que a mesmice na vida do protagonista é percebida como um acúmulo de vazios levando-o a pôr fim à própria existência. Já o conto $O$ escuro das palavras, de Fausto Antônio, envereda para outras concepções da morte, elaborada simbolicamente pelos afrodescendentes, relacionadas com a herança cultural africana ${ }^{15}$, sendo utilizada pelo autor como metáfora de recriação das palavras e dos conceitos. Diferentes temas mereceram a atenção de outros autores do volume 34 de $\mathrm{CN}$, no entanto realizei o presente corte temático por considerar a riqueza

15 Aqui incluo também o texto "O velório", de minha autoria.

196 Número temático: Literatura, cultura e memória negra. A Cor das Letras - UEFS, n. 12, 2011 
das abordagens que merecem um aprofundamento analítico e um tratamento teórico entre os vários que já foram realizados, tomando como base a produção sistemática e contínua da coletânea. Com a leitura do livro e os poucos exemplos apresentados, foi possível constatar que, especialmente neste volume, Cadernos Negros revela uma maturidade literária no trato com a palavra e pelos temas desenvolvidos. Maturidade esta conquistada no fazer literário constante com a preocupação de colocar em primeiro plano o ponto de vista daqueles que raramente são retratados na literatura brasileira, e quando o são ocupam papéis eivados de estereótipos negativos que sobejam em preconceitos raciais explícitos ou subliminares.

Cadernos Negros reafirma a existência de uma literatura negra e inscreve no cenário da literatura brasileira a resistência através da escrita e a conquista de espaços, apertados ainda, mas que vamos alargando com a insistência de nossos verbos e a robustez de nossas vivências substantivas.

\section{REFERÊNCIAS}

ADÚN, Guellwaar. A solidão de Soledade. In: RIBEIRO, Esmeralda; BARBOSA, Márcio. (Org.). Cadernos Negros, v. 34. São Paulo: Quilombhoje, 2011, p. 99-106.

ALVES, Miriam. O velório. In: RIBEIRO, Esmeralda; BARBOSA, Márcio. (Org.). Cadernos Negros, v. 34. São Paulo: Quilombhoje, 2011, p. 143-150.

ANTÔNIO, Fausto. O escuro das palavras. In: RIBEIRO, Esmeralda; BARBOSA, Márcio. (Org.). Cadernos Negros, v. 34. São Paulo: Quilombhoje, 2011, p. 89-97.

EVARISTO, Conceição. Lumbiá. In: RIBEIRO, Esmeralda; BARBOSA, Márcio. (Org.). Cadernos Negros, v. 34. São Paulo: Quilombhoje, 2011, p. 35-40.

EVARISTO, Conceição. Ei, Ardoca. In: RIBEIRO, Esmeralda; BARBOSA, Márcio. (Org.). Cadernos Negros, v. 34. São Paulo: Quilombhoje, 2011, p. 41-44.

KÜBLER-ROSS, Elisabeth. Sobre a morte e o morrer. São Paulo: Martins Fontes, 1998.

PINTO, Jairo. Armandinho, RG desconhecido. In: RIBEIRO, Esmeralda; BARBOSA, Márcio. (Org.). Cadernos Negros, v. 34. São Paulo: Quilombhoje, 2011, p. 117-119.

REIS, João José. A morte é uma festa: ritos fúnebres e revolta popular no Brasil do século XIX. São Paulo: Cia. das Letras, 1991.

SANTOS, Juana Elbein dos. Os Nàgô e a morte: Pàdê, àsèsè e o culto de êgun na Bahia. Petrópolis: Vozes, 1986. 
